\title{
Dynamic risk management: A contemporary approach to process safety management
}

Faisal Khan ${ }^{1}$, Seyed Javad Hashemi ${ }^{1}$, Nicola Paltrinieri ${ }^{2}$, Paul Amyotte ${ }^{3}$, Valerio Cozzani ${ }^{4}$, and Genserik Reniers ${ }^{5}$

1. Centre for Risk, Integrity and Safety Engineering (C-RISE), Faculty of Engineering \& Applied Science, Memorial University of Newfoundland, St. John's, NL A1B 3X5, Canada

2. Department of Production and Quality Engineering, Norwegian University of Science and Technology NTNU, S.P. Andersens veg 5, 7031 Trondheim, Norway

3. Department of Process Engineering and Applied Science, Dalhousie University, Halifax, NS B3J 2X4, Canada

4. Dipartimento di Ingegneria Chimica, Mineraria e delle Tecnologie Ambientali, Alma Mater StudiorumUniversità di Bologna, Bologna, Italy

5. Safety and Security Science Group (S3G), Faculty of Technology, Policy and Management, TU Delft, Delft, The Netherlands

\begin{abstract}
Process accidents in the early 1980s have drawn process safety into the main stream. In the 1990s, risk-based approaches were developed to bring safety into design as well as economic considerations. In the $2000 \mathrm{~s}$, the inherent safety approach began to be practiced on a limited basis, and process safety evolution made significant progress. As process systems continue to become more complex and operations move into remote and harsh environments, traditional risk analysis may no longer be sufficient. Dynamic risk assessment is the basis for the next generation of risk and management approaches that help to enable safer complex process systems operating in extreme environments. This article investigates the main contributions in the area of dynamic risk assessment. Then, an overall framework for dynamic risk management of process facilities is proposed.
\end{abstract}

Keywords: dynamic risk assessment, safety risk, process safety management, risk management

\section{Introduction}

Process safety is a disciplined framework for managing the integrity of operating systems and processes handling hazardous substances [1]. Unlike the occupational safety approach, which 
focuses on hazards that could result in health issues (e.g. slips, trips, and falls), process safety focuses on the prevention and mitigation of process hazards that may result in the release of chemicals or of energy [2]. Such hazards could ultimately result in serious impacts including human health loss, environmental damage, asset loss and loss of production.

As industrialization progressed in the $20^{\text {th }}$ century and more complex technologies developed over time, a series of intermittent catastrophes began to happen in different parts of the world [3]. However, it was mostly after highly publicized, international disasters such as those in Flixborough (United Kingdom, 1974), Seveso (Italy, 1976), and Bhopal (India, 1984) [4] that governments and regulatory agencies began to establish what is now called Process Safety Management (PSM). Continued occurrence of major losses, with some recent examples such as the Texas City refinery accident in 2005 [5] and the Gulf of Mexico's Deepwater Horizon oil spill in 2010 [6], have had a significant impact on the industry's approaches to modern process safety. Consequently, the oil and gas industries recognized that "process safety technology alone, without process safety management, would not prevent catastrophic incidents" [7]. Publications by Andrew Hopkins [8], Trevor Kletz [9], and Atherton \& Gil [10] have served to raise process safety awareness and to publicize the lessons from these and other incidents [1].

The result of this increased awareness has been a global recognition of PSM as the primary approach for establishing the level of safety in operations required to manage high-hazard processes [1]. With this in mind, and also due to the evolution in regulatory thinking that integrated traditional occupational safety with process safety [11], several PSM standards and guidelines were developed by industry associations around the world. Some examples are the OSHA 29 CFR 1910.119 [12] and API RP 750 [13] in the United States, and the PSM Standard [14] published by CSChE in Canada. In Europe, since 1982, such approaches were integrated in 
the EU legislation, with the so-called "Seveso" Directives (Directive 82/501/EEC [15], Directive 96/82/EC [16], Directive 2012/18/EU [17]). All of these PSM programs cover the same basic requirements, although the number of program elements may vary depending on the criteria used [1].

Risk-based approaches were introduced to support the next generation of PSM programs. In Europe, two pilot studies are considered as the precursors of such approaches in chemical clusters: the integrated studies of Canvey Island [18,19] and of the Rijnmond area [20]. In 1988, a project aiming at risk-based decision making was developed in the chemical cluster of Ravenna [21]. In the United Kingdom and in The Netherlands, such methods are now required to support the implementation of Seveso Directives [2,22]. In the United States, however, risk-based approaches to PSM were introduced much later. It was in 2007 that the Center for Chemical Process Safety (CCPS) proposed the introduction of risk-based process safety [11]. The evolution of traditional PSM programs to risk-based approaches is described in the next section.

\section{Risk-Based Process Safety}

Although regulatory agencies around the world have mandated a formal implementation of PSM, incident investigations continue to identify inadequate management system performance as a key contributor to incidents [23]. The unfortunate Deepwater Horizon explosion and oil spill in the Gulf of Mexico in 2010 has raised questions about the likelihood of such an event occurring again. There is a collective need for the chemical and major hazard sectors to demonstrate that risks are being adequately controlled, as the industry and regulators are often judged using the latest major incident to gain public attention [24]. Therefore, evolution of traditional PSM approaches is essential to avoid the degradation of organizations' process safety performance. 
Achieving process safety excellence requires the identification of abnormal process situations and implementation of corrective actions before a serious incident occurs [11]. Built on the analysis of the frequency and consequences of potential accidents, risk analysis is the right tool for the evaluation of a PSM program performance [25,26]. "A risk-based approach reduces the potential for assigning an undue amount of resources to manage lower-risk events, thereby freeing up resources for tasks that address higher-risk events" [11]. Using risk-based process safety (RBPS), the deficiencies of a PSM system can be identified and resources can be assigned accordingly to improve PSM practices. In the US, CCPS's document on RBPS guidelines [11] is the most important risk-based PSM program, which recognizes that all hazards and risks are not equal and that more resources should be focused on higher risks. Although the CCPS has since changed to a risk-based approach that supplements the coverage provided by regulation in the US, CSChE has retained the original CCPS structure for use in Canada [27]. In Europe, however, the risk-based point of view has been put into practice in several countries for many years, and publications such as the Dutch "Purple Book" [22] provide guidelines, practical procedures and data to support such practices. In the European framework, RBPS has been applied to manage, control and reduce the risk in single facilities, but also in large chemical clusters [20] and for land-use planning around chemical sites to reduce the risk for the population [28-30].

Several risk assessment techniques have been developed in recent years by different industries and regulatory agencies. Some examples and reviews of conventional risk assessment can be found in $[11,25,31,32]$. In 2006, an integrated approach to risk assessment based on bow-ties was proposed in Europe as the result of the ARAMIS project [33]. Although conventional risk assessment methods have played an important role in identifying major risks and maintaining safety in process facilities, they have the disadvantage of being static. Moreover, they are often 
using generic failure data [34]. Complex oil and gas facilities have hundreds of dynamic variables, deviation of which can affect the overall process risk [31]. The conditions in process facilities are dynamic, with changes in operating parameters often being reflected in changed operating procedures and equipment [35]. Feed variability, mechanical and operational integrity degradation, wrong setting, improper methods and human error can cause abnormal situations that can eventually result in severe consequences [36]. However, due to their static structure, conventional risk assessment approaches fail to capture the variation of risks as deviations or changes in the process and plant take place [34]. The following section identifies the fundamental steps for conducting the dynamic risk assessment and reviews the major contributions in this area.

\section{Dynamic Risk Assessment}

Any process is subject to deterioration with time due to natural and assignable causes. A dynamic risk assessment (DRA) is defined in this work as a method that updates estimated risk of a deteriorating process according to the performance of the control system, safety barriers, inspection and maintenance activities, the human factor, and procedures.

The main difference between traditional risk assessment methods and a DRA approach can be highlighted using Figure 1, which shows the flowchart of a typical DRA method. Almost all qualitative and quantitative risk analysis methods involve the first three phases identified in Figure 1, including hazard identification, risk assessment, and evaluation of control measures [35]. However, a DRA method includes an additional phase of monitoring and assessing process abnormal conditions to revise the estimated risk. 


\begin{tabular}{|c|c|c|c|c|c|}
\hline \multicolumn{2}{|r|}{ Steps } & $\begin{array}{c}\text { Hazard } \\
\text { Identification }\end{array}$ & $\begin{array}{c}\text { Risk } \\
\text { Assessment }\end{array}$ & $\begin{array}{l}\text { Control } \\
\text { Measures }\end{array}$ & $\begin{array}{l}\text { Incident Monitoring/ } \\
\text { Investigation }\end{array}$ \\
\hline 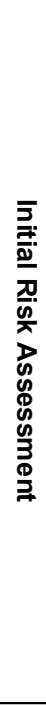 & $\begin{array}{l}\text { Identify and scrutinize inherent } \\
\text { controls in place } \\
\text { Assess consequences } \\
\text { Evaluate the effectiveness of the } \\
\text { process safety management } \\
\text { system } \\
\text { Assess likelihoods and conduct } \\
\text { initial risk assessment }\end{array}$ & $\begin{array}{l}1 \\
1 \\
1 \\
1 \\
1 \\
1 \\
1 \\
1 \\
1 \\
1 \\
1 \\
1 \\
1 \\
1 \\
1 \\
1 \\
1 \\
1 \\
1 \\
1 \\
1 \\
1 \\
1 \\
1 \\
1 \\
1\end{array}$ & $\begin{array}{l}1 \\
1 \\
1 \\
1 \\
1 \\
1 \\
1 \\
1 \\
1 \\
1 \\
1 \\
1 \\
1 \\
1 \\
1 \\
1 \\
1 \\
1 \\
1 \\
1 \\
1 \\
1 \\
1 \\
1 \\
1\end{array}$ & $\rightarrow$ & 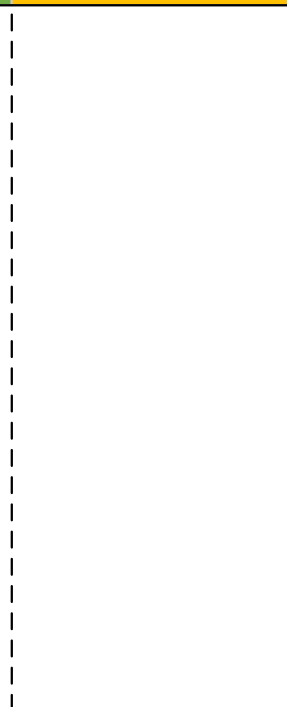 \\
\hline & PDCA Cycle & Plan & Do & Check & Adjust \\
\hline 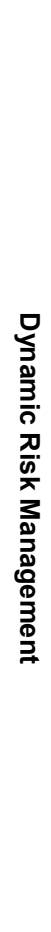 & $\begin{array}{l}\text { Identify and recognize new } \\
\text { potential hazards and accident } \\
\text { scenarios; plan a change } \\
\text { Update estimated risks; test the } \\
\text { change; show residual risks } \\
\text { Compare the residual risk to the } \\
\text { expected risk from "Plan" step; } \\
\text { identify additional controls } \\
\text { required; ensure procedures/ } \\
\text { audits are in place } \\
\text { Prepare/revise performance } \\
\text { standards; apply changes in } \\
\text { control measures/PSM strategies } \\
\text { Conduct incident investigation } \\
\text { using real time data on abnormal } \\
\text { conditions, near misses and/or } \\
\text { failure of safety barriers }\end{array}$ & $\begin{array}{l}1 \\
1 \\
1 \\
1 \\
1 \\
1 \\
1 \\
1 \\
1 \\
1 \\
1 \\
1 \\
1 \\
1 \\
1 \\
1 \\
1 \\
1 \\
1 \\
1 \\
1 \\
1 \\
1 \\
1 \\
1 \\
1 \\
1 \\
1 \\
1 \\
1 \\
1 \\
1 \\
1 \\
1\end{array}$ & $\begin{array}{l}1 \\
1 \\
1 \\
1 \\
1 \\
1 \\
1 \\
1 \\
1 \\
1 \\
1 \\
1 \\
1 \\
1 \\
1 \\
1 \\
1 \\
1 \\
1 \\
1 \\
1 \\
1 \\
1 \\
1 \\
1 \\
1 \\
1 \\
1 \\
\cdots \\
1 \\
1 \\
1\end{array}$ & $\begin{array}{l}1 \\
1 \\
1 \\
1 \\
1 \\
1 \\
1 \\
1 \\
1 \\
1 \\
1 \\
1 \\
1 \\
1 \\
1 \\
1 \\
1 \\
1 \\
1 \\
1 \\
1 \\
1 \\
1 \\
1 \\
1 \\
1 \\
1\end{array}$ & 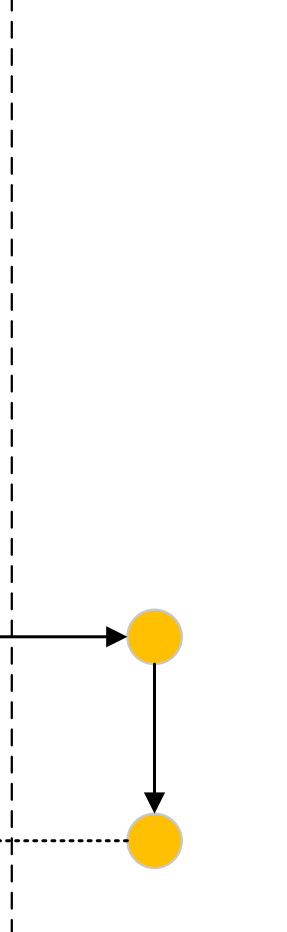 \\
\hline & $\begin{array}{l}\text { Repeat the PDCA cycle based on } \\
\text { the new information }\end{array}$ & & & & 1 \\
\hline
\end{tabular}

Figure 1. Typical dynamic risk analysis and management flowchart 
There have been several contributions in recent years that propose and promote DRA methods [32,34,37-45]. A comprehensive review of these contributions shows that while all the presented approaches share the four main phases identified in Figure 1, they can be distinguished based on the following three criteria:

i. Type of information used

ii. $\quad$ Risk updating mechanism

iii. Probability of failure (POF) updating vs. consequences of failure (COF) updating

Table 1 highlights the major contributions in dynamic risk analysis of process facilities and compares them based on the three criteria above. Table 1 also presents the advantages and disadvantages of each method. As can be seen from Table 1, Bayesian updating using process and failure histories and the bow-tie technique to incorporate new identified potential hazards are two main approaches used in most DRA applications. However, due to the inherent limitations of each of the methods in Table 1, there still exist several knowledge and technological gaps in dynamic risk assessment, which are discussed in the next section.

Table 1. Major contributions in dynamic risk analysis of process facilities

\begin{tabular}{lll}
\hline Method & Description & Related works \\
\hline Bayesian & Information used: Process history, accident precursor data, alarm databases & Meel and Seider \\
& Updating Mechanism: Bayesian updating mechanism is used to update the & {$[27,28]$} \\
& parionani et al. \\
& system. & {$[25,29]$} \\
& $\begin{array}{l}\text { Advantages: } \\
\text { - Capability to handle uncertainty, multi-state variables, complex causal }[47]\end{array}$ & Kalantarnia et al. \\
& relationships, and sequentially dependent failures. & Khakzad et al. [39] \\
& $\begin{array}{l}\text { Disadvantages: } \\
\text { - High computational burden to construct conditional probability tables }\end{array}$ & \\
& - Inability to model complex dependencies among variables & \\
& - Application of deterministic and/or normally distributed probabilities & \\
\hline Bow-tie & Information used: Accident precursor data; new identified scenarios & Paltrinieri et al. \\
\hline
\end{tabular}




\begin{tabular}{|c|c|c|}
\hline Method & Description & \\
\hline & $\begin{array}{l}\text { Updating mechanism: Continuous safety-related information retrieval is } \\
\text { integrated with conventional bow-tie analysis to dynamically estimate the risk } \\
\text { Advantages: } \\
\text { - Simple practical implementation } \\
\text { Disadvantages: } \\
\text { - Limited capability to handle uncertainty, multi-state variables and } \\
\text { dependent failures due to application of simple Boolean functions in bow- } \\
\text { tie analysis } \\
\text { - Application of deterministic probability values } \\
\text { - Inability to model complex dependencies among variables }\end{array}$ & $\begin{array}{l}{[42,43,48]} \\
\text { Pasman and Rogers } \\
\text { [49] } \\
\text { CCPS [50] } \\
\text { Khakzad et al. [51] } \\
\text { Villa et al. [45] }\end{array}$ \\
\hline $\begin{array}{l}\text { Principal } \\
\text { component } \\
\text { analysis } \\
\text { (PCA) }\end{array}$ & $\begin{array}{l}\text { Information used: Process history } \\
\text { Updating mechanism: Probability of a fault is calculated based on the PCA } \\
\text { filtered score, and the severity of the fault is a weighted average of the } \\
\text { consequences of each variable in the score. } \\
\text { Advantages: } \\
\text { - Multivariate techniques } \\
\text { - Takes advantage of the correlation between process input and output } \\
\text { - Extracts latent features from high dimensional data } \\
\text { Disadvantages: } \\
\text { - Relies on linear models and assumes Gaussian noise } \\
\text { - Unable to model complex dependencies among variables } \\
\text { - Most applications require the process model }\end{array}$ & $\begin{array}{l}\text { Jiang and Yang [52] } \\
\text { Ge and Song [53] } \\
\text { Zadakbar et al. [54] }\end{array}$ \\
\hline $\begin{array}{l}\text { Loss } \\
\text { functions }\end{array}$ & $\begin{array}{l}\text { Information used: Deviation of key process characteristics from target values } \\
\text { Updating mechanism: Loss functions are used to relate process deviations to } \\
\text { economic losses } \\
\text { Advantages: } \\
\text { - Provides a mechanism for real-time loss modelling } \\
\text { - Promotes continuous improvement of process safety through proactive } \\
\text { loss minimization } \\
\text { Disadvantages: } \\
\text { - Selection of a proper loss function could be difficult for data-scarce } \\
\text { processes }\end{array}$ & $\begin{array}{l}\text { Hashemi et al. [36] } \\
\text { Zadakbar et al. [55] } \\
\text { Ali [56] } \\
\text { Pan and Chen [57] }\end{array}$ \\
\hline $\begin{array}{l}\text { Risk } \\
\text { barometer }\end{array}$ & $\begin{array}{l}\text { Information used: Technical, operational and organizational indicators } \\
\text { assessing deviation from optimal condition } \\
\text { Updating mechanism: Indicators are used to assess safety barrier } \\
\text { performance on a regular basis, which in turn allows for continuous } \\
\text { assessment of overall risk variation } \\
\text { Advantages: } \\
\text { - Technical indicators are integrated with proactive } \\
\text { operational/organizational indicators in order to assess early deviations }\end{array}$ & $\begin{array}{l}\text { Paltrinieri et al. } \\
{[37,58-60]} \\
\text { Villa et al. [45] } \\
\text { Scarponi et al. [61] }\end{array}$ \\
\hline
\end{tabular}




\begin{tabular}{|c|c|c|}
\hline Method & Description & Related works \\
\hline & $\begin{array}{l}\text { potentially leading to unwanted events } \\
\text { - Degrading safety barriers leading to critical risk increase may be identified } \\
\text { and their improvement may be prioritized }\end{array}$ & \\
\hline & $\begin{array}{l}\text { Disadvantages: } \\
\text { - It is case-specific and partially based on expert judgment from operators. } \\
\text { - Relies on linear models } \\
\text { - It is based on relevant indicators whose collection may be irregular. Such } \\
\text { irregularities may compromise the overall risk assessment. }\end{array}$ & \\
\hline
\end{tabular}

\section{Knowledge and Technological Gaps}

Having evaluated the DRA methods in Table 1, the following technological gaps between the existing methods and the requirements of an effective DRA method according to the definition provided in the previous section are identified as follows:

1. There is no single approach to DRA that can update both POF and COF. Except for the loss function approach that can be used to revise estimated economical loss of a deviated process, all other methods may be considered dynamic in only estimating the probabilities of potential events.

2. In most approaches, it is assumed that a univariate key process characteristic can be assigned to a system.

3. Deterministic point-based probability values are used in most applications, ignoring the uncertainty associated with probability estimations. In some recent developments in Bayesian Network (BN) and PCA-based approaches, normal distribution has been used as the marginal distribution. However, there is no doubt that the assumption of joint normality fails to yield suitable models in many applications

4. Either independent or linearly dependent variables are considered in all applications highlighted in Table 1. In other words, existing models fail to model complex non-linear dependencies among variables influencing overall system risk. 
Although $\mathrm{BN}$ has been used as a general framework for analyzing causal influences among variables to describe multivariate systems, the latter two challenges still exist. The inherent structural limitation of the $\mathrm{BN}$ and bow-tie approaches does not allow consideration of multivariate systems with different marginal distributions and complex non-linear dependencies. Hashemi et al. [62] used an alternate and markedly different approach for constructing multivariate distributions using copula functions for operational loss modelling. However, copulas are unable to capture cause-effect relationships among random variables, and they also cannot make use of available knowledge about causal structures.

From this discussion, it can be concluded that a combination of different mathematical tools would be required to enable the incorporation of different types of process and failure information with different types of potentially complex and correlated marginal distributions. The combination of BN analysis and copula functions is an interesting topic for further research to provide an intuitively compelling framework for modeling causal relationships among (potentially) highly correlated variables with any level of dependence complexity. The resulting Copula Bayesian Network (CBN) model [63] for dynamic probability updating can be integrated with the copula-based multivariate loss modelling proposed in [62] to provide a multivariate technique that can dynamically update both the COF and POF of complex systems with different types of discrete and continuous data and new information from the system.

\section{Dynamic Risk Management}

It has been shown in numerous studies that accidents such as the BP Texas City refinery accident in 2005, the BP Deepwater Horizon disaster in 2010, and other major industrial accidents might have been prevented if a dynamic risk approach like the one presented above was integrated into 
the management framework $[6,43,44]$. However, the implementation of a DRA approach could be a complex, resource-demanding process. Therefore, as described in [44], "a strong safety culture for monitoring and recording process performances and incidents is needed, and a robust decision-making process should be introduced." Developing new risk assessment techniques to overcome identified shortcomings of traditional approaches will not necessarily result in better process safety performance [64]. The integration of risk assessment techniques with management systems along with a strong culture promoting continuous improvement are essential to improve safety $[64,65]$.

To address this requirement, as shown in Figure 2, the integration of the Plan-Do-Check-Adjust (PDCA) management method [66] with the DRA approach is proposed here to develop a new dynamic risk management (DRM) framework, enhancing the one previously suggested by Paltrinieri et al. [43]. Figure 3 shows a simple schematic illustration of how the proposed DRM approach is incorporated into the safety system and compares it with the traditional approach. In the traditional safety system design, variable deviations from their predefined threshold limits are monitored to activate control systems, alarms, and emergency shutdown devices (ESD). However, compared to this conventional single variable-based safety system design approach, the application of the proposed DRM approach ensures continuous updating of the events probabilities based on new evidence from: (i) monitoring of multiple correlated process variables; (ii) failure and incident histories; and (iii) process and operational changes. 


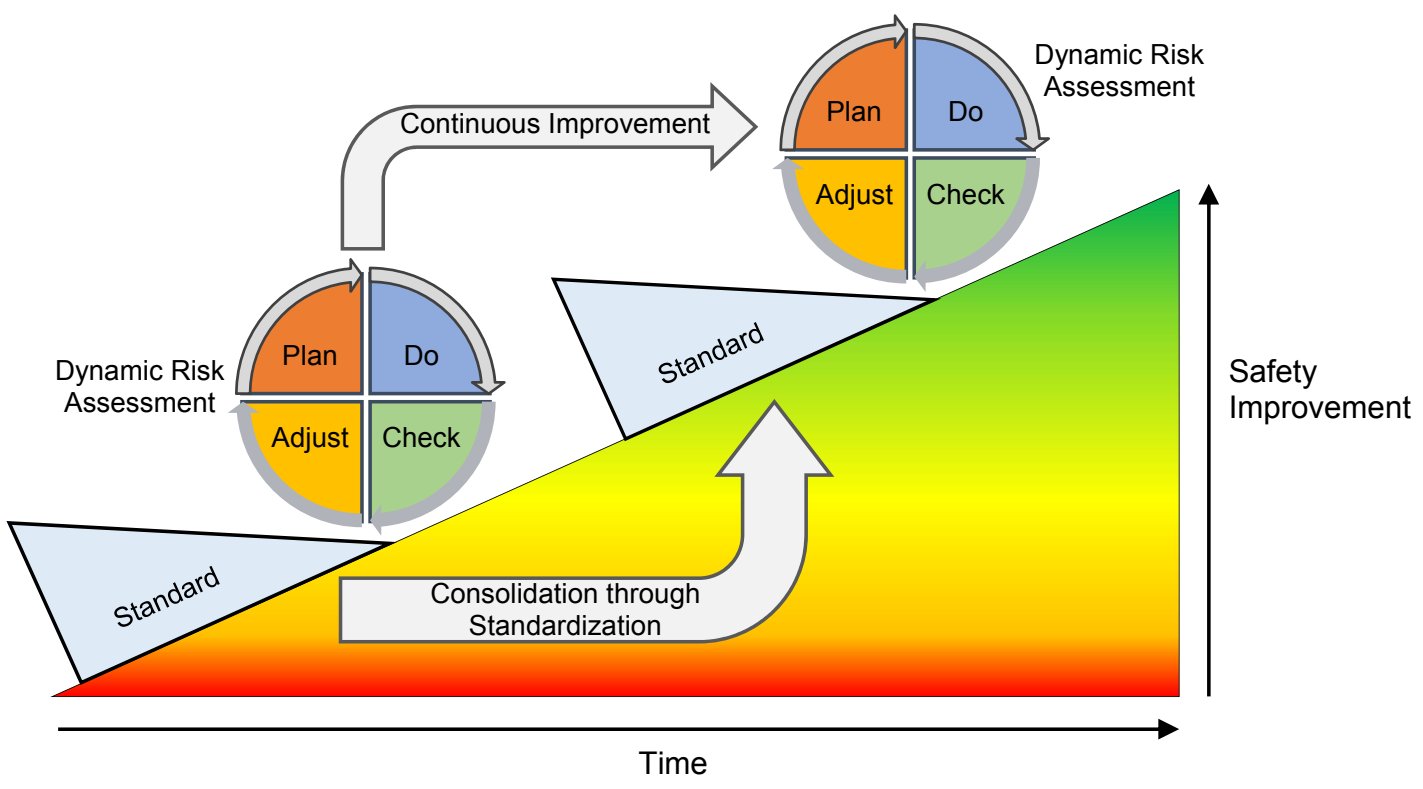

Figure 2. Continuous safety improvement through dynamic risk management; adopted from [66]
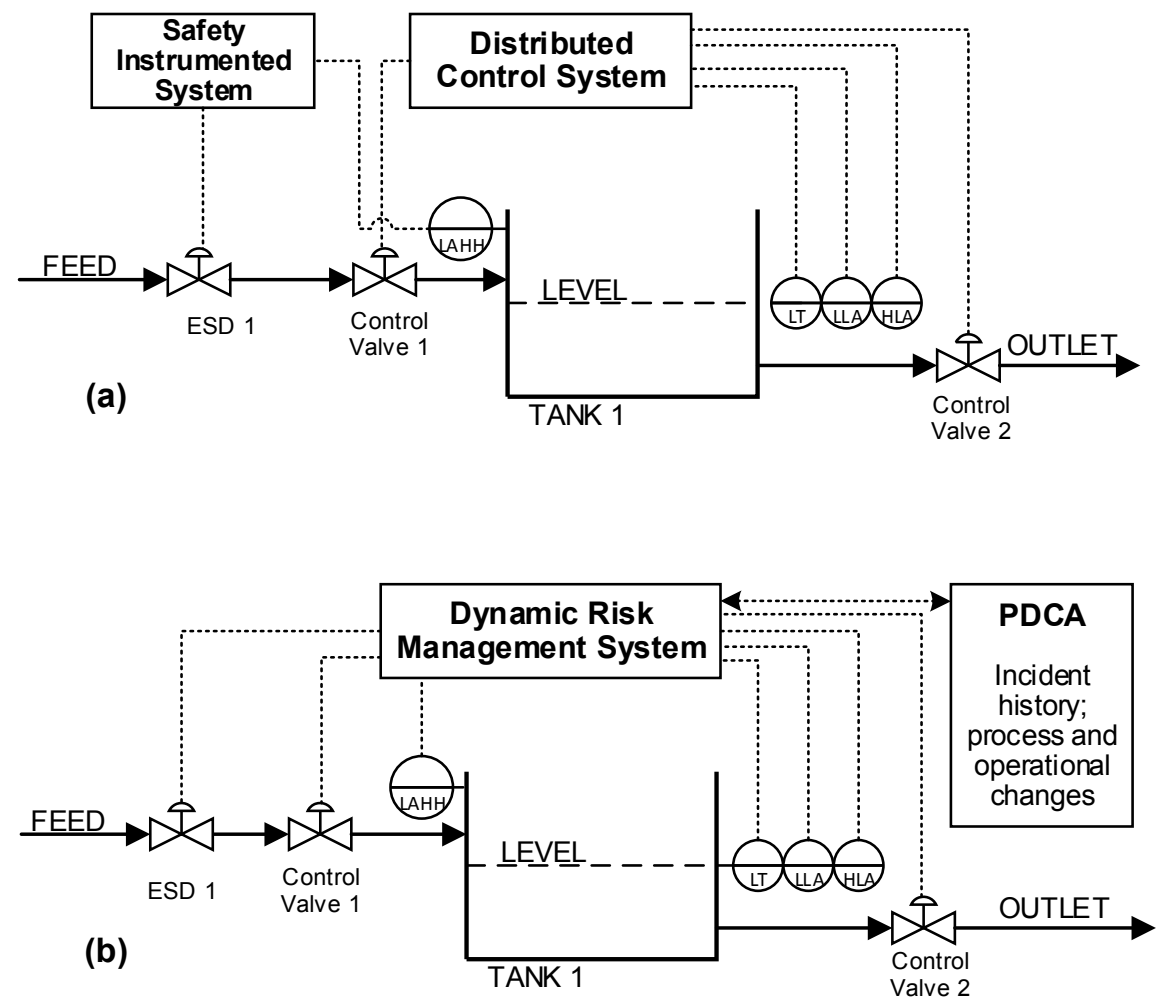

Figure 3. Schematic of a tank system (a) Traditional safety and control system design; (b) Incorporation of the proposed Dynamic Risk Management framework in safety and control system design 
As highlighted in Figure 2, a fundamental principle of the scientific DRA method and PDCA is iteration-once triggered, the presented DRM framework ensures control and continuous improvement of process safety and provides support to avoid the lack of a reporting and learning culture. Repeating the PDCA cycle in the presented DRM framework fosters a "zero-incident" and "zero-defect" culture for process operations. Thinking even further ahead, the incorporation of economic information into the dynamic risk approach would assist managers and decisionmakers to adequately and invest in safety measures, in a timely manner.

The application of the DRM framework may seem demanding and unattractive both because it requires iteration and also involves numerical work. At the same time, however, these are the strengths of dynamic approaches aiming to ensure continuous improvement. The integration of the DRM approach with the day-to-day technical and management workflows, along with a strong safety culture, provide a scientific tool to support the decision-making process and to minimize the associated time by providing a real-time risk estimate. The application of appropriate model selection and sensitivity investigation techniques [63], as well as the implementation of advanced data acquisition systems, are essential for quantitative risk management approaches and to consider the potential model sensitivity to uncertain input data.

\section{Conclusion}

Considering the importance of making decisions based on the real-time risk, there have been efforts to make risk assessment methods dynamically adaptable. Having a dynamic operational risk assessment tool provides a real-time metric to measure and monitor process safety and quality performance. The evolution of risk-based approaches and the main contributions in the area of dynamic risk assessment are reviewed in this paper. Comparing the strengths and 
limitations of the different dynamic risk assessment methods presented, the current technological and management challenges toward development of an efficient and practical dynamic risk management approach are identified. The main limitations of the existing methods identified include: (i) consideration of univariate key characteristics of the system that influences risk; (ii) ignorance of potential complex dependency among risk factors; and (iii) use of deterministic probability values that add to the uncertainty of the estimated risk. Potential approaches to developing a comprehensive and flexible dynamic risk assessment tool to tackle these challenges are discussed.

A dynamic risk management framework is also proposed to ensure continuous improvement of the risk management process based on real-time process performance revised using process and failure history. The application of the dynamic risk management framework enhances the riskinformed decision-making process by constantly monitoring, evaluating and improving the

process performance. Also highlighted is that a good safety culture, as discussed by Dennis Hendershot [64] and Andrew Hopkins [65], is essential in an effective dynamic risk management program.

\section{Acknowledgments}

The first author gratefully acknowledge the financial support provided by the Natural Sciences and Engineering Research Council (NSERC) of Canada, the Research and Development Corporation (RDC) Newfoundland and Labrador, and the Vale Research Chair Grant.

\section{References and recommended reading}

Papers of particular interest, published within the period of review, have been highlighted as: 
- of special interest

•• of outstanding interest

[1] CAPP. Process safety management: Regulatory Scan. Calgary: The Canadian Association of Petroleum Producers (CAPP); 2014. doi:10.1002/prs.11678.

[2] HSE. The Control of Major Accident Hazards (COMAH) Regulations. Third. London: Health and Safety Executive (HSE); 2015.

[3] Macza M. A Canadian Perspective of the History of Process Safety Management Legislation 2008:1-22.

[4] Marsh Risk Consulting. The 100 Largest Losses. London: 2014.

[5] CSB. Investigation Report for BP Texas City Refinery Explosion. Washington, DC: The U.S. Chemical Safety Board; 2007.

[6] CSB. Investigation Report Overview: Explosion and Fire at the Macondo Well. Washington, DC: The U.S. Chemical Safety Board; 2014.

[7] Kraus RS. Developing a Process Safety Management Programme. Int Labour Organ 2011. http://www.iloencyclopaedia.org/component/k2/127-77-chemical-processing/developing-aprocess-safety-management-programme (accessed December 22, 2015).

[8] Hopkins A. Lessons from Longford. Sydney, Australia: CCH Australia; 2000.

[9] Kletz T. Still Going Wrong! : Case Histories of Process Plant Disasters and How They Could Have Been Avoided. Burlington, MA: Gulf Professional Publishing; 2004. doi:10.1016/B978075067709-7/50058-5.

[10] Atherton J, Gil F. Incidents That Define Process Safety. New York: Center for Chemical Process Safety (CCPS); 2008.

[11] CCPS. Guidelines for Risk Based Process Safety. Hoboken, New Jersey: Center for Chemical Process Safety. John Wiley \& Sons, Inc.; 2007.

[12] OSHA. Process Safety Management of Highly Hazardous Chemicals (29 CFR 1910.119). U.S. 
Occupational Safety and Health Administration; 1992.

[13] API. RP 750: Management of Process Hazards. Washington: American Petroleum Institute; 1990.

[14] CSChE. Process Safety Management Standard. First. Ottawa, ON: Canadian Society for Chemical Engineering; 2012.

[15] EC. Council Directive 82/501/EEC of 24 June 1982 on the major-accident hazardsof certain industrial activities. Brussels: Official Journal of the European Communities L230/25; 1982.

[16] EC. Council Directive 96/82/EC of 9 December 1996 on the control of major-accident hazards involving dangerous substances. Brussels: Official Journal of the European Communities L10/13; 1997.

[17] European Commission. European Parliament and Council Directive 2012/18/EU of 4 July 2012 on control of major-accident hazards involving dangerous substances, amending and subsequently repealing council directive 96/82/EC. 2012.

[18] HSE. Canvey: A Second Report. A Review of the Potential Hazards from Operations in the Canvey Island/Thurrock Area Three Years after Publication of the Canvey Report. HM Stationery Office, London: Health and Safety Executive; 1981.

[19] HSE. Canvey: An Investigation of Potential Hazards from Operations in the Canvey Island/Thurrock Area. HM Stationery Office, London: Health and Safety Executive (HSE); 1978.

[20] Rijnmond Public Authority. Risk Analysis of Six Potentially Hazardous Industrial Objects in the Rijnmond Area, a Pilot Study. Reidel, Dordrecht (NL): Springer Science \& Business Media; 1982.

[21] Egidi D, Foraboschi FP, Spadoni G, Amendola A. The ARIPAR project: analysis of the major accident risks connected with industrial and transportation activities in the Ravenna area. Reliab Eng Syst Saf 1995;49:75-89. doi:10.1016/0951-8320(95)00026-X.

[22] Uijt de Haag PAM, Ale BJM. Guidelines for Quantitative Risk Assessment (Purple Book). The Hague (NL): Committee for the Prevention of Disasters; 1999.

[23] CCPS. Risked Based Process Safety Overview. New York: American Institute of Chemical Engineers (AIChE); 2014. 
[24] HSE. Developing process safety indicators. London: Health and Safety Executive; 2006.

[25] API. Recommended Practice 581: Risk-Based Inspection Technology. 3rd ed. Washington: American Petroleum Institute; 2016.

- This standard is one of the most accepted and used standards within the oil and gas industry to implementing quantitative risk-based techniques for inspection scheduling.

[26] CCPS. Guidelines for Chemical Process Quantitative Risk Analysis. Second. New York: Center for Chemical Process Safety of the American Institute of Chemical Engineers; 2000.

[27] CSChE. Process Safety Management Guide. 4th ed. Ottawa, ON: Canadian Society for Chemical Engineering; 2011. doi:10.1201/b11069-30.

[28] Christou MD, Amendola A, Smeder M. The control of major accident hazards: The land-use planning issue. J Hazard Mater 1999;65:151-78. doi:10.1016/S0304-3894(98)00261-1.

[29] Cozzani V, Bandini R, Basta C, Christou MD. Application of land-use planning criteria for the control of major accident hazards: a case-study. J Hazard Mater 2006;136:170-80. doi:10.1016/j.jhazmat.2005.12.031.

[30] Spadoni G, Egidi D, Contini S. Through ARIPAR-GIS the quantified area risk analysis supports land-use planning activities. J Hazard Mater 2000;71:423-37. doi:10.1016/S0304-3894(99)000916.

[31] Oktem UG, Seider WD, Soroush M, Pariyani A. Improve Process Safety with Near-Miss Analysis. Chem Eng Prog 2013;May:20-7.

- This paper is a great example of applying the concept of dynamic risk analysis (DRA) based on alarm databases. It also highlights current research in this area and offers perspective on methodologies most likely to succeed.

[32] Khan F, Rathnayaka S, Ahmed S. Methods and models in process safety and risk management: Past, present and future. Process Saf Environ Prot 2015;98:116-47.

- The paper provides a comprehensive review of past progress in the development of methods 
and models for process safety and risk management, and highlights the present research trends.

[33] Delvosalle C, Fievez C, Pipart A, Debray B. ARAMIS project: a comprehensive methodology for the identification of reference accident scenarios in process industries. J Hazard Mater 2006;130:200-19. doi:10.1016/j.jhazmat.2005.07.005.

[34] Kalantarnia M, Khan F, Hawboldt K. Dynamic risk assessment using failure assessment and Bayesian theory. J Loss Prev Process Ind 2009;22:600-6. doi:10.1016/j.jlp.2009.04.006.

[35] NOPSEMA. Guidance note N-04300-GN0165 Revision 4 - Risk Assessment. Perth, Australia: National Offshore Petroleum Safety and Environmental Management Authority; 2012.

[36] Hashemi SJ, Ahmed S, Khan F. Risk-based operational performance analysis using loss functions. Chem Eng Sci 2014;116:99-108. doi:10.1016/j.ces.2014.04.042.

- This article is one of the first to apply the concept of loss functions for risk-based process performance assessment to overcome the existing challenges in assessing impacts of deviations of process variables on safety and economy of a process operation.

[37] Paltrinieri N, Scarponi G. Addressing Dynamic Risk in the Petroleum Industry by Means of Innovative Analysis Solutions. Chem Eng Trans 2014;36:451-6. doi:10.3303/CET1436076.

- This paper introduces the concept of risk barometer for dynamic risk assessment. Indicators are used to assess safety barrier performance on a regular basis, which in turn allows for continuous assessment of overall risk variation.

[38] Pariyani A, Seider WD, Oktem UG, Soroush M. Dynamic Risk Analysis Using Alarm Databases to Improve Process Safety and Product Quality: Part I - Data Compaction. AIChE J 2012;58:81225. doi:10.1002/aic.12643.

[39] Khakzad N, Khan F, Amyotte P. Dynamic safety analysis of process systems by mapping bow-tie into Bayesian network. Process Saf Environ Prot 2013;91:46-53. doi:10.1016/j.psep.2012.01.005.

- This paper provides a practical algorithm to mapping bow-tie models into Bayesian networks. 
This paper also introduces the application of probability adapting in dynamic safety analysis rather than probability updating.

[40] Meel A, Seider WD. Plant-specific dynamic failure assessment using Bayesian theory. Chem Eng Sci 2006;61:7036-56. doi:10.1016/j.ces.2006.07.007.

[41] Meel A, Seider WD. Real-time risk analysis of safety systems. Comput Chem Eng 2008;32:82740. doi:10.1016/j.compchemeng.2007.03.006.

[42] Paltrinieri N, Tugnoli A, Buston J, Wardman M, Cozzani V. Dynamic Procedure for Atypical Scenarios Identification (DyPASI): A new systematic HAZID tool. J Loss Prev Process Ind 2013;26:683-95. doi:10.1016/j.jlp.2013.01.006.

[43] Paltrinieri N, Khan F, Amyotte P, Cozzani V. Dynamic approach to risk management: Application to the Hoeganaes metal dust accidents. Process Saf Environ Prot 2013;92:669-79. doi:10.1016/j.psep.2013.11.008.

[44] Paltrinieri N, Khan F, Cozzani V. Coupling of advanced techniques for dynamic risk management. J Risk Res 2014. doi:10.1080/13669877.2014.919515.

•- This paper presents an interesting dynamic approach to risk management, which is able to take into account new risk notions and early warnings and to systematically update the related risk.

[45] Villa V, Paltrinieri N, Khan F, Cozzani V. Towards dynamic risk analysis: A review of the risk assessment approach and its limitations in the chemical process industry. Saf Sci 2016;89:77-93. doi:10.1016/j.ssci.2016.06.002.

[46] Pariyani A, Seider WD, Oktem UG, Soroush M. Dynamic Risk Analysis Using Alarm Databases to Improve Process Safety and Product Quality: Part II - Bayesian Analysis. AIChE J 2012;58:826-41. doi:10.1002/aic.12642.

[47] Vinnem JE, Bye R, Gran BA, Kongsvik T, Nyheim OM, Okstad EH, et al. Risk modelling of maintenance work on major process equipment on offshore petroleum installations. J Loss Prev 
Process Ind 2012;25:274-92. doi:10.1016/j.jlp.2011.11.001.

[48] Paltrinieri N, Tugnoli A, Buston J, Wardman M. DyPASI Methodology : from Information Retrieval to Integration of HAZID Process. Chem Eng Trans 2013;32:433-8. doi:10.3303/CET1332073.

[49] Pasman H, Rogers W. How can we use the information provided by process safety performance indicators? Possibilities and limitations. J Loss Prev Process Ind 2014;30:197-206. doi:10.1016/j.jlp.2013.06.001.

[50] CCPS. Guidelines for Hazard Evaluation Procedures. New York: American Institute of Chemical Engineers (AIChE); 2008.

[51] Khakzad N, Khan F, Amyotte P. Dynamic risk analysis using bow-tie approach. Reliab Eng Syst Saf 2012;104:36-44. doi:10.1016/j.ress.2012.04.003.

[52] Jiang Q, Yan X. Nonlinear plant-wide process monitoring using MI-spectral clustering and Bayesian inference-based multiblock KPCA. J Process Control 2015;32:38-50. doi:10.1016/j.jprocont.2015.04.014.

[53] Ge Z, Song Z. Distributed PCA model for plant-wide process monitoring. Ind Eng Chem Res 2013;52:1947-57. doi:10.1021/ie301945s.

[54] Zadakbar O, Imtiaz S, Khan F. Dynamic Risk Assessment and Fault Detection Using Principal Component Analysis. Ind Eng Chem Res 2012;52:809-16. doi:10.1021/ie202880w.

- This paper is one of the first to present a dynamic risk assessment using a comprehensive economic consequence methodology in combination with a multivariate model-based fault detection method.

[55] Zadakbar O, Khan F, Imtiaz S. Dynamic Risk Assessment of a Nonlinear Non-Gaussian System Using a Particle Filter and Detailed Consequence Analysis. Can J Chem Eng 2015;93:1201-11. doi:10.1002/cjce.22212.

[56] Ali S. Mixture of the inverse Rayleigh distribution: Properties and estimation in a Bayesian framework. Appl Math Model 2015;39:515-30. doi:10.1016/j.apm.2014.05.039.

[57] Pan J-N, Chen S-C. A loss-function based approach for evaluating reliability improvement of an 
engineering design. Expert Syst Appl 2013;40:5703-8. doi:10.1016/j.eswa.2013.04.032.

[58] Paltrinieri N, Hauge S, Dionisio M, Nelson WR. Towards a dynamic risk and barrier assessment in an IO context. Safety, Reliab. Risk Anal. Beyond Horiz. - Proc. Eur. Saf. Reliab. Conf. ESREL 2013, Amsterdam, Netherlands: 2014, p. 1915-23. doi:10.1201/b15938-293.

[59] Paltrinieri N, Hauge S, Nelson WR. Dynamic barrier management : A case of sand erosion integrity. Saf. Reliab. Complex Eng. Syst. Proc. Eur. Saf. Reliab. Conf. ESREL 2015, Zurich, Switzerland: 2015, p. 523-31.

[60] Paltrinieri N, Hokstad P. Dynamic risk assessment: Development of a basic structure. Saf. Reliab. Methodol. Appl. - Proc. Eur. Saf. Reliab. Conf. ESREL 2014, Wroclaw, Poland: 2015, p. 138592. doi:10.1201/b17399-191.

[61] Scarponi GE, Paltrinieri N, Khan F, Cozzani V. Reactive and Proactive approaches: tutorials and example. In: Paltrinieri N, Khan FI, editors. Dyn. Risk Anal. Chem. Pet. Ind., Oxford: Butterworth-Heinemann; 2016, p. 284.

- This paper defines the rules of risk barometer for dynamic risk assessment.

[62] Hashemi SJ, Ahmed S, Khan FI. Operational loss modelling for process facilities using multivariate loss functions. Chem Eng Res Des 2015;104:333-45.

-• This paper is one of the first to address both dependencies and cause-effect relationships among risk factors by applying the concept of Copula Bayesian Networks. This paper is a good source of information for researchers involved in multivariate risk analysis.

[63] Hashemi SJ, Khan F, Ahmed S. Multivariate probabilistic safety analysis of process facilities using the Copula Bayesian Network model. Comput Chem Eng 2016:In press.

[64] Hendershot DC. Process Safety Management — You Can't Get It Right Without a Good Safety Culture. Process Saf Prog 2012;31:1-5.

[65] Hopkins A. Safety, Culture and Risk: The Organisational Causes of Disasters. CCH Australia; 2005. 
[66] ISO 9001:2015 Quality management systems - Requirements. Geneva: The International Organization for Standardization; 2015. 